\title{
Examining boredom: Different causes for different coping profiles
}

\author{
Lia M. Daniels ${ }^{a}, *$, Virginia M.C. Tze ${ }^{a}$, Thomas Goetz ${ }^{b}$ \\ a Department of Educational Psychology, University of Alberta, 6-102 Education North, Edmonton, AB, Canada T6G 2G5 \\ b Empirical Educational Research, University of Konstanz/Thurgau University of Teacher Education, Universitaetsstraße 10, 78457 Konstanz, Germany
}

\section{A R T I C L E I N F O}

Keywords:

Precursors to boredom

Boredom coping strategies

University students

Latent profile analysis

\begin{abstract}
A B S T R A C T
Research has shown that boredom impedes students' academic functioning. Although recent studies have iden tified varying causes of boredom in school settings and the effectiveness of cognitive approach coping in manag ing this negative emotion, little is known about how the perceived causes of boredom relate to coping with boredom. According to the contextual approach to coping, certain forms of coping may be linked to different situational causes of boredom. Therefore, the purposes of this study were twofold: First, we examined university students' strategies to cope with boredom using person centered data analytical approach. Second, we evaluated how the identified boredom coping profiles differed according to particular causes of boredom using a variable centered data analytical approach. We identified three boredom coping profiles consistent with previous findings Reappraisers, Criticizers, and Evaders. Significant differences in eight antecedents to boredom were found among the three profiles. We discuss the implications of the findings for instructors and students.
\end{abstract}

Although students' learning motivation and emotions have long been a major focus in educational research, only recently has academic boredom one of the most common emotions received attention in the literature (e.g., Acee et al., 2010; Daniels et al., 2008; Goetz et al., 2014; Kanevsky \& Keighley, 2003). In our own work, (Daniels, 2010; Tze, 2011) almost $40 \%$ of undergraduate students reported being bored in class at some point. Moreover, boredom experienced in aca demic contexts has been shown to be a debilitating emotion that ad versely influences students' educational development (Pekrun, Goetz, Daniels, Stupnisky, \& Perry, 2010; Pekrun, Hall, Goetz, \& Perry, 2014). In particular, the effects of boredom extend well beyond a transient neg ative affective experience (Barnett, 2005) and are associated with lower academic attainment (Pekrun et al., 2010), dropping out of school (Wegner, Flisher, Chikobvu, Lombard, \& King, 2008) and juvenile delin quency (Newberry \& Duncan, 2001).

Given the accumulating evidence, researchers and educators have begun to consider what causes boredom and how students cope with it. The factors contributing to boredom represent variations of control and value appraisals such as a lack of control, choice, challenge, and meaning (e.g., Acee et al., 2010; Kanevsky \& Keighley, 2003; Tze, Daniels, \& Klassen, 2014). In turn, not all strategies to cope with bore dom are equal and some students cope with boredom better than others (Nett, Goetz, \& Daniels, 2010; Nett, Goetz, \& Hall, 2011; Tze, Daniels, Klassen, \& Li, 2013). Despite recent attention to the causes of boredom and ways to cope with this emotion in separate studies, investigations have not taken into account the relationships between causes of and

\footnotetext{
* Corresponding author. Tel.: + 17804924761.

E-mail addresses: lia.daniels@ualberta.ca (L.M. Daniels),virginiatze@ualberta.ca (V.M.C. Tze), thomas.goetz@uni-konstanz.de (T. Goetz).
}

ways to cope with boredom. Research has shown that the effectiveness of any particular approach to coping depends on the circumstances that provoked the need to cope in the first place (Aldwin, 2007). For bore dom specifically, linking causes and coping would allow teachers to better design course curriculum to minimize problematic causes of students' boredom and would allow interventions to increase students' abilities to cope with boredom triggered by specific causes. Therefore, the purposes of this study were to identify university students' boredom coping profiles, and to examine how these profiles differ according to perceived causes of boredom.

\subsection{Academic boredom}

Academic boredom can be defined as a multidimensional emotion, involving an unpleasant feeling (affective), low arousal (physiological), a desire to leave the boring situation (motivational), and a perception of slowness in time (cognitive) (Pekrun, 2006). Because of the multidi mensional nature of boredom, it is considered a unique emotion that differs from simply a lack of interest (Pekrun et al., 2010). In particular, Goetz and Hall (2014) discuss that the unpleasant feeling and inclina tion to withdraw from a situation distinguish boredom from a lack of interest, which typically is not associated with these affective and moti vational sensations.

\subsection{Causes of boredom}

Because of the negative impact of boredom on learning researchers turned their attention to factors that contribute to the experience of boredom. Goetz and Hall (2014) divide potential antecedents of bore dom into three broad categories: the environment (e.g., monotony, 
isolation, repetition, etc.); the person (e.g., low control/value, boredom proneness, etc.); and the environment/person fit (e.g., too high/too low difficulty, etc.). We adhere to Pekrun's (2006) control value theory of emotion that suggests boredom occurs when students experience a lack of control that is either far beyond or below their abilities (Goetz, Pekrun, Hall, \& Haag, 2006) and they do not perceive value in their aca demic tasks (Pekrun, Goetz, Frenzel, Barchfeld, \& Perry, 2011). These control and value appraisals are based on students' assessments of the environment and their personality factors, thus mapping onto the cate gories identified by Goetz and Hall (2014). For instance, when paired with low value of the content, students who perceive listening to didac tic lectures as very low control will likely experience boredom in that class. This would be even more likely for individuals high on boredom proneness, a personality factor that inclines an individual to appraise a situation as boring (e.g., Farmer \& Sundberg, 1986; Mann \& Robinson, 2009).

Given both environment and person factors appear to contribute to the experience of boredom, Daschmann, Goetz, and Stupnisky (2011) developed the Precursors to Boredom Scales (PBS) in order to evaluate multiple causes of boredom in school settings. Building on other work addressing potential antecedents to boredom (e.g., Loukidou, Loan Clarke, \& Daniels, 2009; Martin, Sadlo, \& Stew, 2006), Daschmann et al. identified eight discrete factors that contribute to boredom: being over challenged, being under challenged, being bored by an unchang ing routine, not finding meaning in learning, having better things to do than be in class, disliking the teacher, feeling uninvolved, and being bored in general. The first seven reasons pertain to environmental factors that can be appraised as either supporting or hindering control and value. The final cause, general boredom tendency, was included to refer to dispositional causes of boredom (e.g., Farmer \& Sundberg, 1986; Vodanovich \& Kass, 1990).

Next, Daschmann et al. (2011) examined how the eight distin guishable causes of boredom related to teachers' instructional qual ity and students' achievement. Seven of the eight causes correlated negatively with effective instructional qualities, reflective of the sit uational basis for boredom. For example, boredom due to lack of in volvement showed the strongest negative correlation with student adaptive instruction, $r=-.69$, and general boredom tendency showed the smallest negative correlation with the same construct, $r=-.30$. Interestingly, boredom due to under challenge demon strated a significant positive relationship with student adaptive in struction, $r=.26$, and with math grades, $r=.44$, among middle school students in Germany. Using a validated English version of the PBS, Tze, Daniels, Klassen (2014) found that only over challenge, lack of meaning, opportunity costs, and general boredom tendency, but not other causes of boredom, were negatively related to university students' self efficacy for self regulated learning. In ad dition to the PBS, researchers have shown that boredom may be caused by a cycle of low achievement (Pekrun et al., 2014) and ward ed off by high perceptions of autonomy support (Tze, Klassen, \& Daniels, 2014) and supportive teacher characteristics (Goetz, Lüdtkec, Nett, Kellera, \& Lipneviche, 2013). These reports provide some guidance on the major contributors of boredom rooted in appraisals of the environment and thus may shape the effectiveness of certain coping strategies.

\subsection{Boredom coping strategies}

It is important to identify effective boredom coping strategies for in stances when, despite trying to reduce the causes of boredom, students nonetheless experience the emotion. Based on Holahan's framework of coping with stress (Holahan, Moos, \& Schaefer, 1996), Nett et al. (2010) developed the Boredom Coping Scale (BCS) from a sample of Grades 510 German students. The BCS consists of four categories: cognitive approach, behavioral approach, cognitive avoidance, and behavioral avoidance coping. Cognitive approach coping involves increasing control/value appraisals of boring situations, and behavioral approach coping involves taking action to alter boring situations thereby increas ing control/value. Cognitive avoidance and behavioral avoidance strat egies involve cognitive and physical disengagement, respectively, from boring situations. Cognitive approach strategies were negatively relat ed to frequency of boredom and positively associated with value in learning (Nett et al., 2010, 2011); whereas, both cognitive avoidance and behavioral avoidance coping were positively related to the occur rence of boredom and negatively related to effort in learning.

Students likely combine various coping strategies to manage their boredom because coping strategies are not mutually exclusive. Nett et al. (2010) used latent profile analysis and identified three groups of students: Reappraisers, Criticizers, and Evaders. Reappraisers primarily endorsed cognitive approach strategies and Criticizers predominantly adopted behavioral approach coping; whereas, Evaders preferred cognitive avoidance and behavioral avoidance strategies. In subse quent work Nett et al. (2011) found only the Reappraiser and Evader profiles. Tze, Klassen, Daniels, Li, and Zhang (2013) also found slightly different coping profiles for Canadian and Chinese students. Specifically, the Reappraiser and Criticizer profiles emerged for Canadian university students but there was no Evader profile. The Evader profile was com mon for Chinese students along with two additional coping profiles: In frequent Copers who were low on all coping strategies and Reformers who were high on all strategies except behavioral avoidance. In Nett et al. $(2010,2011)$ the Reappraiser profile was consistently the most adaptive as evidenced by lower boredom, sustained interest and effort, and higher levels of agreeableness and conscientiousness. In contrast, Reappraisers and Criticizers did not differ in their perceptions of bore dom in Tze, Klassen, Daniels et al.'s (2013) research and Criticizers actu ally reported significantly more intrinsic motivation than Reappraisers. One reason for these differences in effectiveness between profiles may be their appraisals for the cause of boredom in the first place.

\subsection{Theoretical rationale of the present study}

The purpose of this study was to investigate the extent to which students' boredom coping profiles may depend on perceived causes of boredom. Borrowing from the research literature on stress, we argue that causes and coping are linked in theory because "more transitory situation based factors shape people's choices of coping responses" (Holahan et al., 1996, p. 25; see also Lazarus \& Folkman, 1984). Because precursors to boredom reflect students' subjective control and value appraisals of their learning environment, they may indeed function as a situational influence on coping. Imagine for example the following two students in the same course: One student feels bored because the teacher does not make the meaning of the content explicit but can cope by cognitively engaging and creating meaning himself. In contrast, the second student feels bored because she does the same thing in class everyday and copes by not attending. To explore these ideas we used person centered analytical approach to identify university students' boredom coping profiles. We hypothesized that the three coping profiles Reappraisers, Criticizers, and Evaders found in Nett et al. (2010) would emerge in our university student sample. We also exam ined differences between boredom coping profiles and antecedents to boredom. Specifically, we hypothesized that each identified coping profile would vary in the extent to which it emerged in response to dif ferent precursors to boredom.

\section{Method}

\subsection{Participants and procedure}

A total of 446 students registered at a Canadian University were recruited through a participant pool in the Faculty of Education in ex change for research credit. Participants were made aware of the partic ipation pool in their first class and instructed to sign up for a study 
convenient to their schedules. When students signed up for the study, which had a non identifying name, they received the email address of the research assistant managing the project. They contacted the re searcher to receive the link for the online questionnaire administered through SurveyMonkey@ and completed it at their leisure and required approximately $30 \mathrm{~min}$. Consent was implied by completion of the ques tionnaire. Of the participants, 102 were male and 329 were female, with 15 students not reporting their gender. The mean age of the participants was $22.79(S D=5.08)$. No other demographic information is available on the participants.

\subsection{Measures}

\subsubsection{Precursors to boredom}

Causes of boredom were measured with 22 items from the E PBS, the English version of Daschmann et al.'s (2011) PBS. The PBS was designed to assess eight precursors to boredom on a 5 point scale ( 1 [strongly disagree] to 5 [strongly agree]). Each item began with a common statement (i.e., "When I am bored in class it is because...") followed by an antecedent of boredom classified in one of eight catego ries over challenge (e.g. the subject matter is too difficult for me), under challenge (e.g., the subject matter is so easy), monotony (e.g., we always do the same thing in class), lack of meaning (e.g., the subject matter in class has no meaning in my life), opportunity costs (e.g., there are much better things to do than sit in class), teacher dislike (e.g., I don't like my instructor), low involvement (e.g., the instructor never involves us in the lesson), and general boredom (e.g., I am some body who is always bored). The E PBS has shown adequate reliability and validity in past studies (e.g., Tze, Daniels, \& Klassen, 2014). Descrip tive statistics and reliabilities for all variables are in Table 1.

\subsubsection{Boredom coping strategies}

The BCS (Nett et al., 2010) was used to measure students' coping strategies. The BCS consists of 20 items measuring four different ways of coping with boredom: cognitive approach (e.g., I try to pay attention to the lesson more), behavioral approach (e.g., I ask my instructor for more interesting tasks), cognitive avoidance (e.g., I think about my homework or something I have to study), and behavioral avoidance (e.g., I talk to the person sitting next to me). Each set of strategies was measured by five items on a 5 point scale (1 [strongly disagree] to 5 [strongly agree]). The English version of the BCS has shown adequate reliability and validity in previous research with Canadian students (Tze, Klassen, Daniels, Li, \& Zhang, 2013).

\subsection{Plan of analysis}

Our analyses took both a person centered and variable centered approach to examine relationships between causes of and coping with boredom. First, along with other descriptive statistics we correlated all variables to examine bivariate relationships (Table 1). Second, recogniz ing that students use a combination of coping strategies (Nett et al., 2010), we used latent profile analysis (LPA) to identify profiles of coping. The best fitting latent profile solution, conducted in MPlus (Muthén \& Muthén, 1998 2010), was evaluated using the Bayesian Information Criterion (BIC; Schwarz, 1978), Entropy (Zhao \& Karypic, 2004), and Lo Mendell Rubin Test (LMRT; Lo, Mendell, \& Rubin, 2001). The smaller the BIC values, the closer the Entropy value to 1.0, and a significant $p$ value of LMRT indicate an adequate fit of profiles with our data (Lo et al., 2001; Zhao \& Karypic, 2004). Third, we used ANOVA to evaluate how each coping profile differed on the perceived causes of boredom. To control for multiple comparisons we adjusted the alpha level using the Scheffé test.

\section{Results}

\subsection{Correlation analyses}

Table 1 presents zero order Pearson product moment correlations between all study variables. With respect to precursors to boredom, high positive correlations between teacher dislike and lack of involve ment and between under challenge and monotony indicated close con ceptual relationships among those precursors. Consistent with Nett et al.'s $(2010,2011)$ findings, cognitive approach coping was negatively correlated with both cognitive and behavioral avoidance strategies. Additionally, cognitive approach strategies were negatively correlated with most of the precursors to boredom, whereas both cognitive and behavioral avoidance strategies were positively correlated with all the precursors. Behavioral approach strategies showed positive correla tions with over challenge, teacher dislike, lack of involvement, and gen eral boredom. We should note that although many correlations were statistically significant and in the expected direction, the coefficients are small to medium at best in magnitude.

\subsection{Latent profiles of boredom coping}

Table 2 shows the criteria values for the LPA. The LMRT showed that both a three class and a four class solution were significantly better fitting than a more parsimonious solution $(k-1)$. Although BIC was

Table 1

Descriptive statistic and correlations of study variables.

\begin{tabular}{|c|c|c|c|c|c|c|c|c|c|c|c|c|c|c|c|c|}
\hline & & $\alpha$ & $M$ & $S D$ & 1 & 2 & 3 & 4 & 5 & 6 & 7 & 8 & 9 & 10 & 11 & 12 \\
\hline \multicolumn{17}{|c|}{ Precursors to Boredom Scales } \\
\hline 1 & Over-challenged $(\#=4)$ & .89 & 2.23 & 1.03 & & .01 & $.22^{* *}$ & $.43^{* *}$ & $.23^{* *}$ & $.34^{* *}$ & $.41^{* *}$ & $.17^{* *}$ & .06 & $.16^{* *}$ & $.16^{* *}$ & $.12^{*}$ \\
\hline 2 & Under-challenged $(\#=2)$ & .93 & 2.97 & 1.22 & & & $.53^{* *}$ & $.27^{* *}$ & $.16^{* *}$ & $.18^{* *}$ & $.20^{* *}$ & .08 & $.11^{*}$ & .04 & $.22^{* *}$ & $.17^{* *}$ \\
\hline 3 & Monotony $(\#=3)$ & .89 & 3.01 & 1.21 & & & & $.47^{* *}$ & $.35^{* *}$ & $.36^{* *}$ & $.45^{* *}$ & $.23^{* *}$ & $.06^{*}$ & .03 & $.26^{* *}$ & $.31^{* *}$ \\
\hline 4 & Lack of meaning $(\#=4)$ & .93 & 2.45 & 1.18 & & & & & $.47^{* *}$ & $.42^{* *}$ & $.46^{* *}$ & $.23^{* *}$ & $.12^{*}$ & $.10^{*}$ & $.23^{* *}$ & $.32^{* *}$ \\
\hline 5 & Opportunity costs $(\#=2)$ & .92 & 2.84 & 1.25 & & & & & & $.22^{* *}$ & $.21^{* *}$ & $.34^{* *}$ & $.20^{*}$ & .04 & $.33^{* *}$ & $.32^{* *}$ \\
\hline 6 & Teacher dislike $(\#=2)$ & .91 & 2.06 & 1.15 & & & & & & & $.63^{* *}$ & .17 & $.10^{*}$ & $.14^{* *}$ & $.22^{* *}$ & $.19^{* *}$ \\
\hline 7 & Lack of involvement $(\#=2)$ & .90 & 2.37 & 1.27 & & & & & & & & $.15^{* *}$ & .07 & $.14^{* *}$ & $.26^{* *}$ & $.19^{* *}$ \\
\hline 8 & General boredom $(\#=3)$ & .83 & 1.77 & 0.84 & & & & & & & & & $.17^{*}$ & $.19^{* *}$ & $.19^{* *}$ & $.30^{* *}$ \\
\hline \multicolumn{17}{|c|}{ Boredom Coping Scale } \\
\hline 9 & Cognitive-approach $(\#=5)$ & .90 & 3.59 & 0.89 & & & & & & & & & & .00 & $.14^{* *}$ & $.25^{* *}$ \\
\hline 10 & Behavioral-approach $(\#=5)$ & .92 & 1.43 & 0.67 & & & & & & & & & & & $.21^{* *}$ & $.13^{*}$ \\
\hline 11 & Cognitive-avoidance $(\#=5)$ & .87 & 2.56 & 1.00 & & & & & & & & & & & & $.36^{* *}$ \\
\hline 12 & Behavioral-avoidance $(\#=5)$ & .97 & 2.14 & 1.13 & & & & & & & & & & & & \\
\hline
\end{tabular}

Note. $M$ and $S D$ refer to the averaged item score within each scale.

${ }^{*} p<.05$. ${ }^{* *} p<.01$. 
Table 2

Criteria values of the latent profile analysis.

\begin{tabular}{|c|c|c|c|c|c|c|}
\hline & No. of class & & & & & \\
\hline & 1 & 2 & 3 & 4 & 5 & 6 \\
\hline Number of free parameters & 8 & 13 & 18 & 23 & 28 & 33 \\
\hline Log likelihood & 4912.56 & 4830.33 & 4759.12 & 4681.97 & 4669.85 & 4592.03 \\
\hline Bayesian (BIC) & 9873.42 & 9739.15 & 9626.91 & 9502.80 & 9508.76 & 9383.31 \\
\hline Entropy & & 0.82 & 0.860 & 0.897 & 0.890 & 0.838 \\
\hline$p$ of Lo-Mendel-Rubin test & & 0 & 0.0048 & 0.0023 & 0.8005 & 0.2671 \\
\hline
\end{tabular}

lower and the Entropy was higher in the four class solution than the three class solution, a closer examination of the additional class in the four class solution revealed that it could be subsumed under one of the other three classes. This additional profile indeed showed a pattern of results similar to Criticizers' profile. In light of this, the three class solution was chosen for subsequent analysis.

To identify how the three latent groups differed on the four coping strategies, standardized mean factor scores for these variables were calculated and are presented in Fig. 1 . The first profile $(n=279)$ pre ferred cognitive approach coping $\left(M_{\mathrm{COAP}}=.16, M_{\mathrm{BEAP}}=-.25\right.$, $M_{\mathrm{COAV}}=-.26, M_{\mathrm{BEAV}}=-.55$ ), like the Reappraisers' profile (Nett et al., 2010). The second profile $(\mathrm{n}=39)$ showed a strong preference for behavioral approach coping $\left(M_{\mathrm{COAP}}=-.10, M_{\mathrm{BEAP}}=2.33\right.$, $M_{\mathrm{COAV}}=.41, M_{\mathrm{BEAV}}=.39$ ), like the Criticizers' profile. The third profile $(\mathrm{n}=103)$ showed predominant adoption of cognitive avoidance and behavioral avoidance strategies $\left(M_{\mathrm{COAP}}=-.39, M_{\mathrm{BEAP}}=-.24\right.$, $\left.M_{\mathrm{COAV}}=.56, M_{\mathrm{BEAV}}=1.34\right)$ aligning with the Evader's profile.

\subsection{Differences in antecedents to boredom}

Univariate analysis of variance revealed significant group differences for each of the individual precursors to boredom. Table 3 shows the re sults of the post hoc analyses and Fig. 2 provides a visual representation of the means. There were no significant differences between Evaders and Criticizers on any of the eight causes of boredom. However, when compared to Reappraisers, the Evader profile emerged when students attributed their boredom to every possible cause except teacher dislike. In other words, students who felt bored because of a range of causes in cluding being over challenged, being under challenged, monotony, lack of meaning, opportunity costs, lack of involvement, and generalized boredom tendency were more likely to adopt the Evaders coping profile than the Reappraisers profile. When Criticizers were compared to Reappraisers a smaller number of causes of boredom distinguished the groups. Specifically, when students perceived their boredom as due to over challenge, lack of meaning, teacher dislike, lack of involvement, and generalized boredom they were more likely to adopt the Criticizers coping profile than the Reappraisers profile. Interestingly, although Crit icizers and Evaders did not differ from each other, the one cause that distinguished them differently from Reappraisers was teacher dislike.

\section{Discussion}

The purpose of our study was to investigate how coping profiles might depend on the perceived causes of boredom. The contribution of our study is fourfold. First, although our study confirms the original three coping profiles reported by Nett et al. (2010) the level of behavioral approach in the Criticizer profile requires discussion. Second, Evaders reported significantly higher levels of all causes of boredom than Reappraisers, except for teacher dislike. Third, along with three other causes, teacher dislike was significantly higher in the Criticizer profile than the Reappraiser profile. Fourth, Criticizers and Evaders reported higher levels of trait boredom than Reappraisers.

\subsection{Boredom coping profiles}

Results of the latent profile analysis were in line with our expecta tions: Each of the three coping profiles identified in Nett et al. (2010) emerged even though previous research had not identified Evaders with Canadian college students (Tze, Daniels, Klassen, \& Li, 2013). Although the overall pattern of the three profiles found in our study was consistent with Nett et al.'s (2010) findings, the college Criticizers appear to endorse very high levels of behavioral approach coping $(M=2.33)$ compared to Nett et al.'s middle school criticizers $(M<$ 1.50 ). From a developmental perspective, college students are usually emerging adults and thus are high in identity explorations, self focus, and possibilities (Arnett, 2007), all of which may contribute to a stron ger ability to "criticize" than early adolescents who are only beginning to forge their independence. Also, Canadian college students pay for

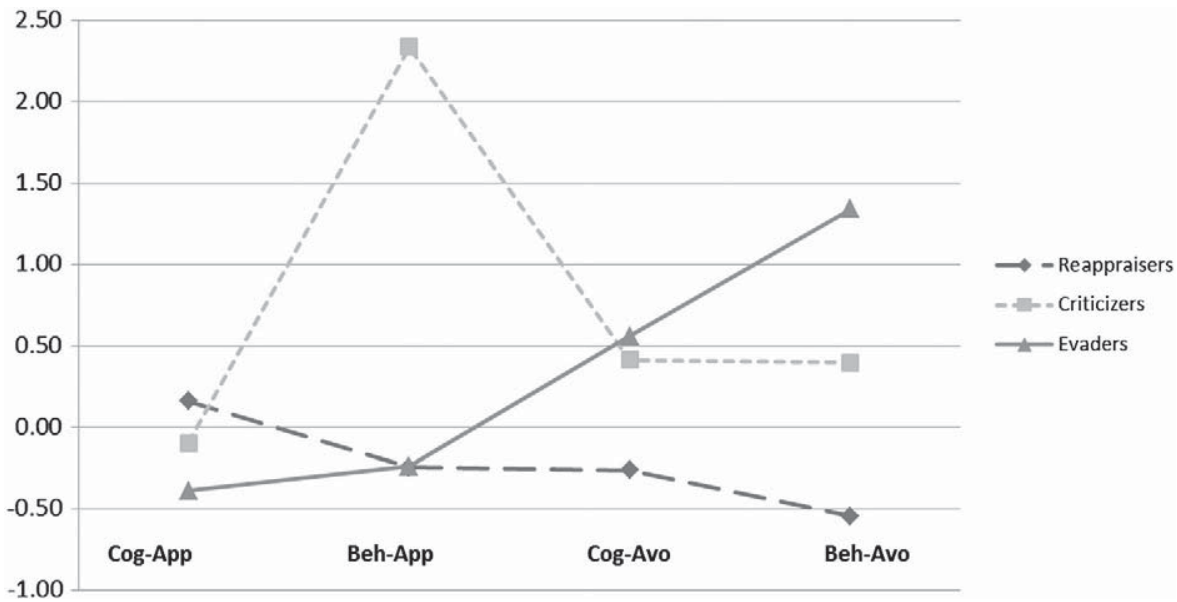

Fig. 1. Latent profiles: The effect of causes on coping with boredom. 
Table 3

Post-hoc analysis on each cause of boredom.

\begin{tabular}{|c|c|c|c|c|c|c|}
\hline & \multicolumn{2}{|c|}{ Reappraisers } & \multicolumn{2}{|c|}{ Criticizers } & \multicolumn{2}{|c|}{ Evaders } \\
\hline & $M$ & $S D$ & $M$ & $S D$ & $M$ & $S D$ \\
\hline Over-challenged & $8.44^{\mathrm{ab}}$ & $(4.03)$ & $10.49^{\mathrm{a}}$ & $(4,20)$ & $9.67^{b}$ & $(4.18)$ \\
\hline Under-challenged & $5.68^{b}$ & $(2.42)$ & 6.00 & $(2,20)$ & $6.63^{b}$ & $(2.49)$ \\
\hline Monotony & $8.37^{b}$ & (3.51) & 9.23 & (3.05) & $10.74^{\mathrm{b}}$ & (3.61) \\
\hline Lack of meaning & $8.93^{\mathrm{ab}}$ & $(4.47)$ & $11.15^{\mathrm{a}}$ & (3.82) & $11.67^{\mathrm{b}}$ & $(5.04)$ \\
\hline Opportunity costs & $5.30^{\mathrm{b}}$ & $(2,47)$ & 5.72 & (1.99) & $6.70^{b}$ & $(2.50)$ \\
\hline Teacher dislike & $3.86 a$ & $(2.29)$ & $5.05^{a}$ & (1.97) & 4.49 & (2.27) \\
\hline Lack of involvement & $4.39^{\mathrm{ab}}$ & $(2.46)$ & $5.54^{\mathrm{a}}$ & $(2.14)$ & $5.40^{\mathrm{b}}$ & (2.71) \\
\hline General boredom & $4.87^{\mathrm{ab}}$ & $(2.24)$ & $6.59^{\mathrm{a}}$ & $(2.82)$ & $6.01^{\mathrm{b}}$ & (2.87) \\
\hline
\end{tabular}

Note. Superscripts ${ }^{\mathrm{a}}$ and ${ }^{\mathrm{b}}$ denote significant Scheffé post-hoc comparisons at $p<.05$ level between Reappraisers and Criticizers, and Reappraisers and Evaders, respectively.

their post secondary education and a recent trend shows an all time high level of academic entitlement (Boswell, 2012) that may extend to making demands on their instructors to reduce boredom. Finally, we should be caution in comparing these mean levels because the data come from different countries in addition to different age groups and we do not have evidence of strong scalar invariance, which is necessary to compare mean levels (Chen, 2008).

\subsection{Differences in causes of boredom}

Seven of the eight possible causes of boredom were more strongly endorsed by Evaders than Reappraisers, suggesting that as the number and intensity of causes of boredom increase students become more inclined to cope with their boredom through avoidance coping strate gies. This finding is problematic: In earlier research Evaders appeared to be the least adaptive coping profile as evidenced by lower academic achievement, more frequent experiences of boredom (Nett et al., 2010), less agreeableness and conscientiousness (Nett et al., 2011) and lower self regulation and intrinsic motivation (Tze, Daniels, Klassen, \& Li, 2013). And yet our findings suggest that as the sources of boredom increase so does the likelihood of following the Evaders profile even if it is unsuccessful. The resultant vicious cycle is easy to understand: Imagine the student who is bored because some things are too easy, other things are too hard, the lecture is not involving or meaningful, and they would rather be out with their friends. Which cause should this student attempt to reappraise? What critique of the instructor should the student leverage? Perhaps when students are un able to pinpoint the source of their boredom avoidance becomes the only viable coping strategy. Because avoidant strategies are not very successful these students may only find more sources of boredom rather than relief from the emotion: In other words the reciprocal relationship between causes and coping must be explored. The cross sectional na ture of our data makes us unable to tease apart these effects and we sug gest further research using longitudinal data and experience sampling methods (e.g., Goetz et al., 2014; Pekrun et al., 2014).

Criticizers differed from Reappraisers on four causes of boredom in addition to boredom tendency, the most notable of which is boredom due to teacher dislike. Like Evaders, Criticizers perceived their boredom as rooted in learning materials that were too difficult and a variety of situational causes likely leading to very low value appraisals. However, when paired with negative feelings towards the instructors, coping characterized by high levels of behavioral approach as seen in the Crit icizers' profile became the preferred solution. Perhaps these students think "I don't really like this teacher so I might as well complain about her practices." It would be interesting in future research to record the specific types of behavioral approach strategies these students employ. For example, do they ask their instructors for less homework, easier exams, or more test preparation to try and mitigate boredom caused by over challenge or do they email their instructor requesting class time involve more active participation to try and resolve boredom asso ciated with low meaning and involvement? In part this decision may depend on which situational precursor is most strongly associated with teacher dislike which according to our correlational analyses would suggest boredom due to lack of meaning and lack of involvement may be the first targets.

Finally, students who viewed their boredom as a stable personality factor of general boredom were more likely cope through either the Evader or Criticizer profile. In this way, Evaders and Criticizers may view their experiences of boredom as a relatively chronic experience that is perhaps unlikely to be resolved by cognitive reappraisal of the situation. Unfortunately, this reveals another vicious cycle in which students who are most likely to report their boredom as stemming

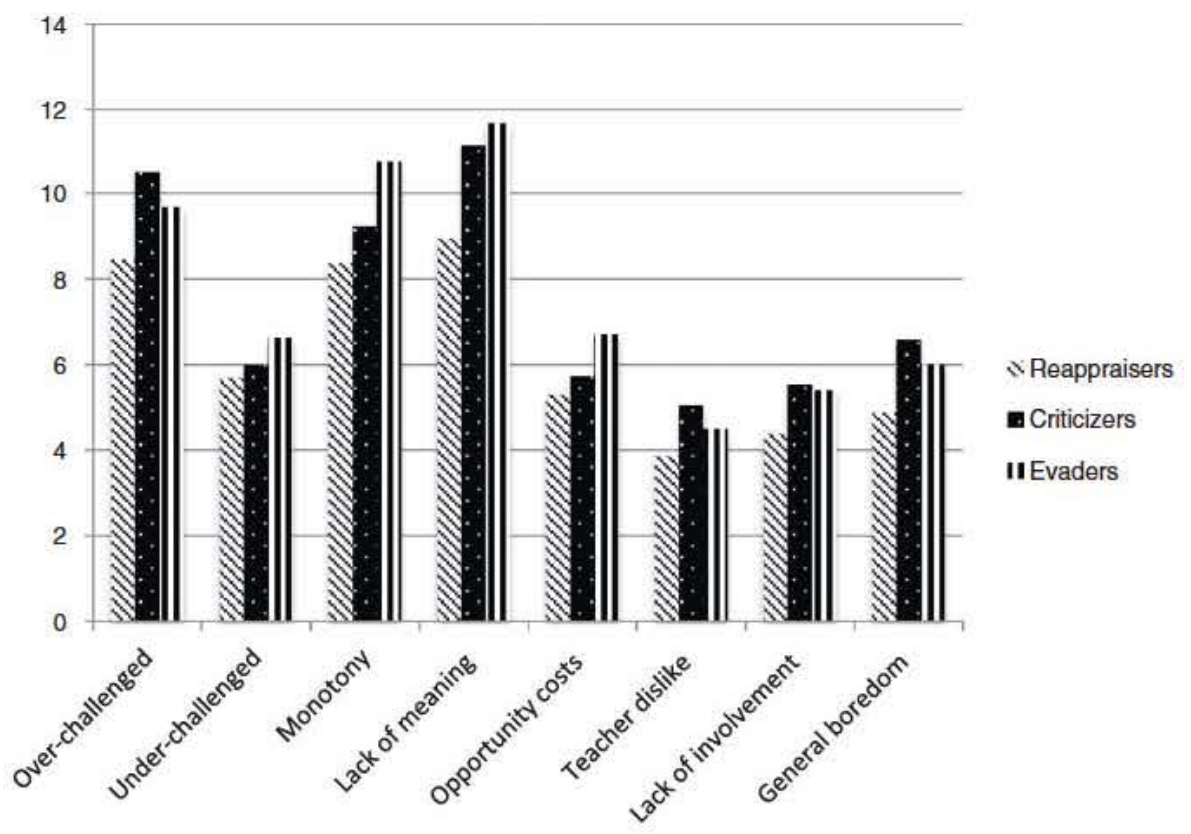

Fig. 2. Mean differences on causes of boredom by boredom coping profile. 
from a trait cause are also those who are unlikely to choose the most effective profile of coping strategies namely, they are unlikely to be Reappraisers.

\subsection{Limitations and future research}

Although our study builds on Nett et al.'s (2011) suggestion that it is important to evaluate how causes are related to students' coping, the current study has some limitations that call for future investigation. First, the study is limited by a relative imbalance in numbers of males and females, representing mainly the responses of female university students in a Faculty of Education. Future research needs to focus on recruiting a more equally balanced sample of male and female students and gathering more demographic information. Although gender was not part of our main research question it is interesting to note that distribution of males and females in each latent profiles is similar to the overall sample. ${ }^{1}$ Second, this study is limited by cross sectional data. Recent research on boredom has focused on reciprocal relation ships with antecedents over time (e.g., Pekrun et al., 2014), specific types of boredom (e.g., Goetz et al., 2014), and experience sampling methodologies (e.g., Nett et al., 2011). We encourage researchers to continue with these methods for exploring boredom, causes, and ante cedents. We would also encourage researchers to consider the benefit of qualitative information in exploring the reasons behind choosing a par ticular coping approach over others. Third, despite identifying three profiles of coping with boredom and showing that they differ based on the cause of boredom, the effectiveness of these profiles in managing this unsettling emotion was not examined in this particular study. This objective was beyond the scope of the current study and has been ex amined in previous research (e.g., Nett et al., 2010, 2011; Tze, Daniels, Klassen, \& Li, 2013) and must be addressed in future research that in cludes a wide range of academic outcomes. Because we did not assess actual reductions in boredom we keep our implications for practice to a minimum.

Criticizers and Evaders were more likely than Reappraisers to view their boredom as caused by over challenge, low involvement, and lack of meaning and therefore we suggest instructors revise their instruction to minimize these specific causes. For example, instructors can try to ensure an appropriate level of challenge (Ames, 1992) by providing their lecture notes to students prior to class, co creating marking rubrics with students, and minimizing time pressure on assignments and exams. Instructors can focus on actively discussing the meaning or value of their content (Wigfield \& Eccles, 2000) and designing courses that allow for high levels of student participation. Technology including student response systems (Trees \& Jackson, 2007), a wide range of on line videos such as TED talks (Miller, 2009), and various forms of social media (Young, 2012) and Web 2.0 technologies may greatly facilitate these endeavours especially in large college classes.

For students, we suggest they learn about adaptive ways to cope with boredom because it is unlikely to be completely ameliorated by in structors' efforts. There is currently no specific intervention designed to train students in boredom coping strategies or to help them identify controllable causes of boredom. Because the precursors to boredom represent appraisals to overly low or high control and lack of value (Pekrun, 2006), cognitive interventions that aim at modifying students' perceptions of control and value may be helpful. One such intervention is Attributional Retraining, which encourages students to identify con trollable rather than uncontrollable causes for outcomes (Haynes, Perry, Stupnisky, \& Daniels, 2009). Equipped with an increased under standing of the effectiveness of re appraisal for combating boredom and the problems associated with avoidance strategies, Evaders and Criticizers may be able to re appraise certain causes for their boredom thus taking on more of a Reappraisers profile. Whether and how

${ }^{1}$ The proportion of females in each latent profile: Reappraiser 79\%; Criticizer 86\%; Evader $86 \% ; F(2,404)=1.24, p=.29$. students move from less effective to more effective coping profiles depending on the causes of their boredom, however, remains yet an other area for research.

\section{Acknowledgments}

This research was supported by a Social Sciences and Humanities Research Council of Canada (SSHRCC) Standard Operating Grant awarded to Dr. Lia Daniels (410 2009 0172).

\section{References}

Acee, T.W., Kim, H., Kim, H.J., Kim, J., Chu, H.R., Kim, M., et al. (2010). Academic boredom in under- and over-challenging situations. Contemporary Educational Psychology, 35, 17-27, http://dx.doi.org/10.1016/j.cedpsych.2009.08.002.

Aldwin, C.M. (2007). Stress, coping, and development: An integrative perspective (2nd ed.). New York: Guilford Press.

Ames, C. (1992). Classrooms: Goals, structures, and student motivation. Journal of Educational Psychology, 84(3), 261-271, http://dx.doi.org/10.1037/0022-0663.84.3. 261.

Arnett, J.J. (2007). Emerging adulthood: What is it, and what is it good for? Child Development Perspectives, 1(2), 68-73, http://dx.doi.org/10.1111/j.1750-8606.2007. 00016.x.

Barnett, L.A. (2005). Measuring the ABCs of leisure experience: Awareness, boredom, challenge, distress. Leisure Sciences, 27(2), 131-155.

Boswell, S.S. (2012) "I deserve success": Academic entitlement attitudes and their relationships with course self-efficacy, social networking, and demographic variables. Social Psychology of Education, 15, 353-365.

Chen, F.F. (2008). What happens if we compare chopsticks with forks? The impact of making inappropriate comparisons in cross-cultural research. Journal of Personality and Social Psychology, 95, 1005-1018, http://dx.doi.org/10.1037/a0013193.

Daniels, L. M. (2010). Data summary on boredom, http://dx.doi.org/10.1037/a0013193 Retrieved from http://emotionandmotivation.files.wordpress.com/2010/07/ boredom-data-summary_oct-18.pdf.

Daniels, L.M., Haynes, T.L., Stupnisky, R.H., Perry, R.P., Newall, N., \& Pekrun, R. (2008). Individual differences in achievement goals: A longitudinal study of cognitive, emotional, and achievement outcomes. Contemporary Educational Psychology, 33, 584-608, http://dx.doi.org/10.1016/j.cedpsych.2007.08.002.

Daschmann, E.C., Goetz, T., \& Stupnisky, R.H. (2011). Testing the predictors of boredom at schools: Development and validation of the precursors to boredom scales. British Journal of Educational Psychology, 81, 421-440, http://dx.doi.org/10.1348/00070 $990 \times 526038$

Farmer, R., \& Sundberg, N.D. (1986). Boredom-proneness-The development and correlates of a new scale. Journal of Personality Assessment, 50, 4-17, http://dx.doi.org/10. 1207/s15327752jpa5001_2.

Goetz, T., Frenzel, A.C., Hall, N.C., Nett, U., Pekrun, R., \& Lipnevich, A. (2014). Types of boredom: An experience sampling approach. Motivation and Emotion, 50, 401-419, http://dx.doi.org/10.1007/s11031-013-9385-y.

Goetz, T., \& Hall, N.C. (2014). Academic boredom. In R. Pekrun, \& L. Linnenbrink-Garcia (Eds.), International Handbook of Emotions in Education (pp. 311-330). New York: Routledge.

Goetz, T., Lüdtkec, O., Nett, U.E., Kellera, M.M., \& Lipneviche, A.A. (2013). Characteristics of teaching and students emotions in the classroom: Investigating differences across domains. Contemporary Educational Psychology, 38, 383-394, http://dx.doi.org/10.1016/ j.cedpsych.2013.08.001.

Goetz, T., Pekrun, R., Hall, N., \& Haag, L. (2006). Academic emotions from a socialcognitive perspective: Antecedents and domain specificity of students' affect in the context of Latin instruction. British Journal of Educational Psychology, 76, 289-308, http://dx.doi.org/10.1348/000709905X42860.

Haynes, T.L., Perry, R.P., Stupnisky, R.H., \& Daniels, L.M. (2009). Attributional retraining in higher education. In J.C. Smart (Ed.), Handbook of Research in Higher Education, Vol. 24. (pp. 227-272). New York: Springer.

Holahan, C.J., Moos, R.H., \& Schaefer, J.A. (1996). Coping, stress resistance, and growth: Conceptualizing adaptive functioning. In M. Zeidner, \& N.S. Endler (Eds.), Handbook of coping. Theory, research, applications. New York: John Wiley \& Sons, Inc.

Kanevsky, L., \& Keighley, T. (2003). To produce or not to produce? Understanding boredom and the honor in underachievement. Roeper Review, 26(1), 20-28.

Lazarus, R.S., \& Folkman, S. (1984). Stress, appraisal, and coping. New York: Springer.

Lo, Y., Mendell, N.R., \& Rubin, D.B. (2001). Testing the number of components in a normal mixture. Biometrika, 88, 767-778, http://dx.doi.org/10.1093/biomet/88.3.767.

Loukidou, L., Loan-Clarke, J., \& Daniels, K. (2009). Boredom in the workplace: More than monotonous tasks. International Journal of Management Reviews, 11, 381-405, http://dx.doi.org/10.1111/j.1468-2370.2009.00267.x.

Mann, S., \& Robinson, A. (2009). Boredom in the lecture theatre: An investigation into the contributors, moderators, and outcomes of boredom amongst university students. British Educational Research Journal, 35, 243-258, http://dx.doi.org/10.1080/ 0141192080204291.

Martin, M. Sadlo, G., \& Stew, G. (2006). The phenomenon of boredom Qualitative Research in Psychology, 3, 193-211, http://dx.doi.org/10.1191/1478088706qrp066oa.

Miller, M.V. (2009). Integrating online multimedia into college course and classroom: With application to the social sciences. Journal of Online Learning and Teaching, 5 (Retrieved from http://jolt.merlot.org/vol5no2/miller_0609). 
Muthén, L.K., \& Muthén, B.O. (1998-2010). Mplus user's guide (6th ed.). Los Angeles, CA: Muthén \& Muthén.

Nett, U.E., Goetz, T., \& Daniels, L.M. (2010). What to do when feeling bored? Students' strategies for coping with boredom. Learning and Individual Differences, 20, 626-638, http://dx.doi.org/10.1016/j.lindif.2010.09.004.

Nett, U.E., Goetz, T., \& Hall, N.C. (2011). Coping with boredom in school: An experience sampling perspective. Contemporary Educational Psychology, 36, 49-59, http://dx. doi.org/10.1016/j.cedpsych.2010.10.003.

Newberry, A.L., \& Duncan, R.D. (2001). Roles of boredom and life goals in juvenile delinquency. Journal of Applied Social Psychology, 31, 527-541, http://dx.doi.org/10. 1111/j.1559-1816.2001.tb02054.

Pekrun, R. (2006). The control-value theory of achievement emotions: Assumptions, corollaries, and implications for educational research and practice. Educational Psychology Review, 18, 315-341, http://dx.doi.org/10.1007/ s10648-006-9029-9.

Pekrun, R., Goetz, T., Daniels, L., Stupnisky, R.H., \& Perry, R.P. (2010). Boredom in academic settings: Exploring control-value antecedents and performance outcomes of a neglected emotion. Journal of Educational Psychology, 531-549, http://dx.doi.org/10. 1037/a0019243.

Pekrun, R., Goetz, T., Frenzel, A.C., Barchfeld, P., \& Perry, R.P. (2011). Measuring emotions in students' learning and performance: The Achievement Emotions Questionnaire (AEQ). Contemporary Educational Psychology, 36, 36-48, http://dx.doi.org/10.1016/j. cedpsych.2010.10.002

Pekrun, R. Hall, N.C. Goetz, T. \& Perry, R. P. (2014). Boredom and academic achievement: Testing a model of reciprocal effects. Journal of Educational Psychology, http://dx. doi.org/10.1037/a0036006.

Schwarz, G. (1978). Estimating the dimension of a model. The Annals of Statistics, 6, 461-464, http://dx.doi.org/10.1214/aos/1176344136.

Trees, A.R., \& Jackson, M.H. (2007). The learning environment in clicker classrooms: Student processes of learning and involvement in large university-level courses using student response systems, Learning, Media, and Technology, 32, 21-40, http://dx.doi.org/10.1080/17439880601141179.

Tze, M. C. (2011). Investigating academic boredom in Canadian and Chinese students. (Unpublished master's thesis), http://dx.doi.org/10.1080/17439880601141179 (Retrieved from: http://hdl.handle.net/10402/era.27791).

Tze, V.M.C., Daniels, L.M., \& Klassen, R.M. (2014). Examining the factor structure and validity of the English Precursors to Boredom Scales. Learning and Individual Differences, 32, 254-260, http://dx.doi.org/10.1016/j.lindif.2014.03.018.

Tze, V.M.C., Daniels, L.M., Klassen, R.M., \& Li, J.C. -H. (2013). Canadian and Chinese university students' approaches to coping with academic boredom. Learning and Individual Differences, 23, 32-43, http://dx.doi.org/10.1016/j.lindif.2012.10.015.

Tze, V.M.C., Klassen, R.M., \& Daniels, L.M. (2014). Patterns of boredom and its relationship with perceived autonomy support and engagement. Contemporary Educational Psychology, 39, 175-187, http://dx.doi.org/10.1016/j.cedpsych.2014.05.001.

Tze V.M.C. Klassen R.M. Daniels, L M. Li. J.C - -H \& Zhang X. (2013). A cross-cultural validation of the Learning-Related Boredom Scale (LRBS) with Canadian and Chinese college students. Journal of Psychoeducational Assessment, 31, 29-40, http://dx.doi. org/10.1177/0734282912443670.

Vodanovich, S.J., \& Kass, S.J. (1990). A factor analytic study of the Boredom Proneness Scale. Journal of Personality Assessment, 55, 115-123.

Wegner, L., Flisher, A.J., Chikobvu, P., Lombard, C., \& King, G. (2008). Leisure boredom and high school dropout in Cape Town, South Africa. Journal of Adolescence, 31, 421-431, http://dx.doi.org/10.1016/j.adolescence.2007.09.004.

Wigfield, A., \& Eccles, J.S. (2000). Expectancy-value theory of achievement motivation. Contemporary Educational Psychology, 25, 68-81.

Young, J.R. (2012). A tech-happy professor reboots after hearing his teaching advice isn' working. The Chronicle of Higher Education (Retrieved from http://chronicle.com/ article/A-Tech-Happy-Professor-Reboots/130741/)

Zhao, Y., \& Karypic, G. (2004). Empirical and theoretical comparisons of selected criterion functions for document clustering. Machine Learning, 55, 311-331. 